TAO, Vol. 15, No. 2, 111-132, June 2004

\title{
Effects of Reduced Yangtze River Discharge on the Circulation of Surrounding Seas
}

\author{
Hung-Jen Lee ${ }^{1}$ ** Shenn-Yu Chao ${ }^{2}$ and Kon-Kee Liu ${ }^{3}$ \\ (Manuscript received 2 September 2003, in final form 30 January 2004)
}

\begin{abstract}
A regional model of the western Pacific Ocean with $1 / 6^{\circ}$ resolution is used to investigate possible effects of reduced Yangtze River discharge on the circulation of surrounding seas. To the extent of data availability, the model is mostly driven by monthly climatological winds and inflows/outflows through open-ocean boundaries. With climatological discharge rate, the Yangtze River plume disperses to the northeast in summer but follows the China Coastal Current (CCC) to the south in winter. While a substantial amount of the summer plume is retained in the southern Yellow Sea and northern East China Sea until the arrival of winter northerly monsoon, the winter Yangtze River discharge is able to escape freely to the south through advection by the $\mathrm{CCC}$. The source water of the $\mathrm{CCC}$ is mainly comprised of winter discharge from Yangtze River, remnants of Yangtze River plume water retained in areas northeast of the river mouth from the preceding summer, Yellow Sea water and even some of the Bohai water. The effect of reduced Yangtze River discharge is highly asymmetric between summer and winter. Summer reduction produces an expansive, positive salinity anomaly northeast of the Yangtze River mouth. The response is rather swift and directly proportional to the reduction of freshwater supply. Winter reduction of freshwater discharge from the Yangtze River leads to higher salinity in the $\mathrm{CCC}$ south of the river mouth. The winter insensitivity of the $\mathrm{CCC}$ to reduced Yangtze outflow arises because the $\mathrm{CCC}$ is fed by multiple sources, some of which are not related to winter discharge
\end{abstract}

${ }^{1}$ National Museum of Marine Biology and Aquarium, 2 Houwan Road, Checheng, Pingtung, Taiwan, $\mathrm{ROC}$

2 Horn Point Laboratory, University of Maryland Center for Environmental Science, Cambridge, 216130775, USA

3 Institute of Hydrological Science, National Central University, Chung_Li, Taiwan, ROC

* Corresponding author address.Dr. Hung-Jen Lee, National Museum of Marine Biology and Aquarium, 2 Houwan Road, Checheng, Pingtung, Taiwan, ROC; E-mail: lec@nmmba.gov.tw 


\section{from Yangtze River. In the highly unlikely event that the Yangtze River discharge is terminated for multiple years, the source water of the CCC will be dominated by the Yellow Sea and even Bohai waters.}

(Key words: Yangtze River Plume, Satellite image, Tracer concentration )

\section{INTRODUCTION}

The Yangtze River (Fig. 1), or Changjiang, discharges over $928 \mathrm{~km}^{3}$ of water annually (Zhang et al. 1990). The discharge also carries more than $4.68 \times 10^{8}$ tons $\mathrm{yr}^{-1}$ of sediments (Huang et al. 2001) and a large amount of nutrients into the East China Sea (ECS) (Zhang 1996). The river plume as indicated by the Changjiang Diluted Water $(\mathrm{S}<32 \mathrm{psu})$ may extend more than hundreds of kilometers away from the river mouth (Beardsley et al., 1985; Gong et al. 1996; Lee and Chao 2003). The rich supply of nutrients and sediments supports high primary productivity and active biogeochemical processes in and around the East China Sea. The largest dam in the world, Three Gorges Dam, is currently under construction in the middle reach of the river and is expected to be operational in 2009. Possible impacts of the dam to the coastal environment are becoming a major concern of the oceanic community.

Damming generally reduces the strength and alters the seasonality of river runoff. Further, the biogeochemistry of surrounding seas is also likely altered. Drawing experiences from the past, the Farakka Dam on the Ganges River in India has led to 75 percent reduction of water flowing to Bangladesh (Chen 2000). The Aswan Dam on the Nile River reduced freshwater and sediment flux entering the Mediterranean, decreasing fish catches in the offshore region (Chen 2000). Constructions and dams on the Yellow River in China, combined with low rainfall due to El Nino effects, have led to about 50 percent drop of water discharge to the Bohai Sea in recent years (Milliman 1997). At the present time, it is difficult to predict the percentage reduction and seasonality of the Yangtze River discharge after damming. If damming is solely for the generation of hydroelectric power, the regulated discharge will likely have a reduced seasonal variation, but the net discharge per year will change little. If some of the water is retained for other usage, then the net annual discharge will be reduced as well.

Despite uncertainties regarding future net discharge and seasonal variation, possible consequences of the altered Yangtze outflow are beginning to attract attention. For example, a steady-state box model of Chen (2000) suggested that a 10 percent reduction in Yangtze outflow would reduce the cross-shelf water exchange between shelf waters and the western Pacific by about 9 percent along the continental margin of the East China Sea. Even more recently, a numerical model simulation (Delcroix and Murtugudde 2002) suggested that reduced Yangtze outflow leads to higher salinity, colder sea surface temperature and weakened anticyclonic circulation in the catchment area. Delcroix and Murtugudde (2002) used a rather coarse $\left(1 / 4^{\circ} \sim 1 / 2^{\circ}\right)$ resolution model and truncated areas shallower than the open ocean mixed-layer depth, including nearshore areas off the China coast, Bohai and the northern portion of the Yellow Sea. Further, the Yangtze River discharge was treated as a surface freshwater flux. 


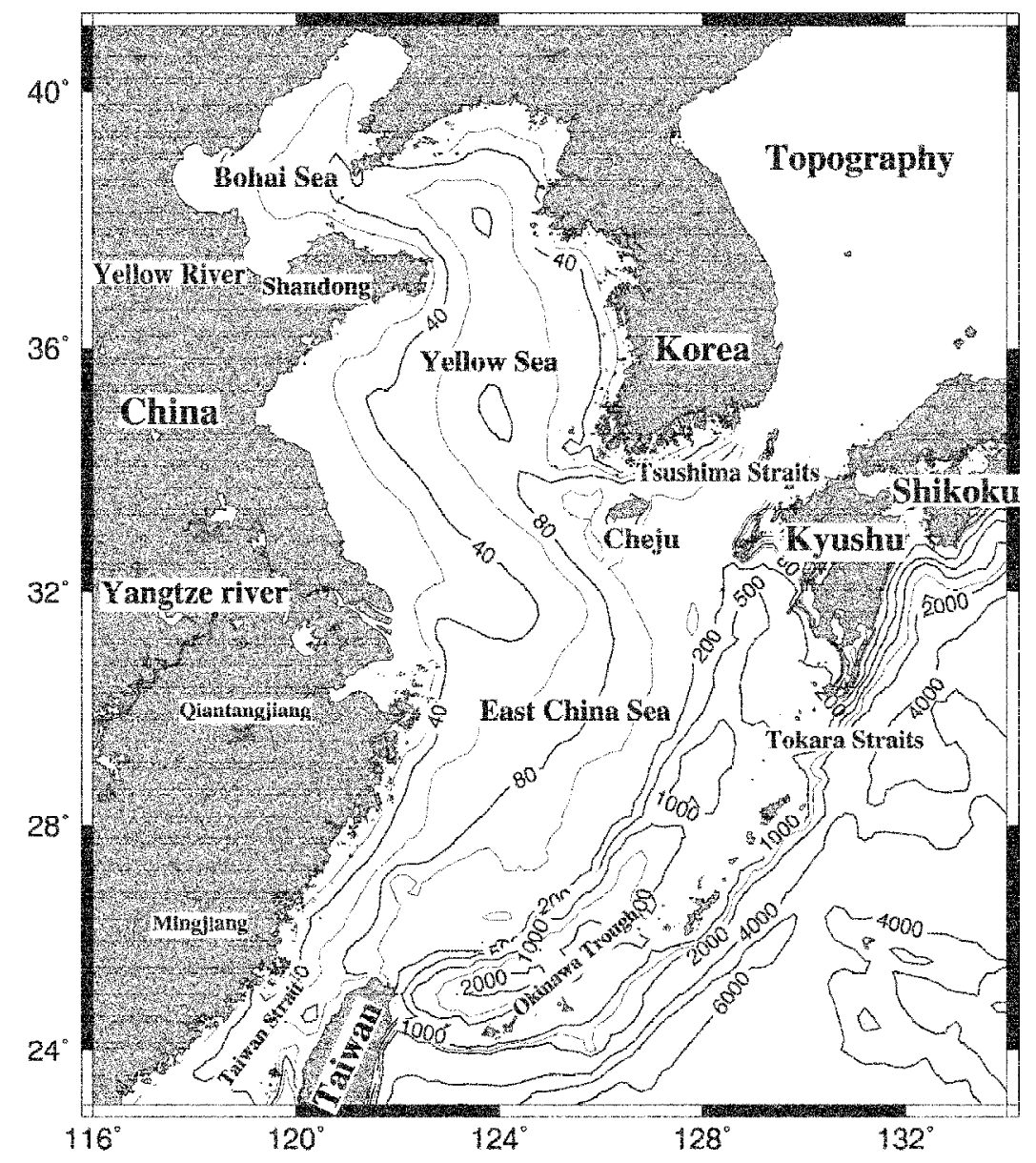

Fig. 1. Bathymetry (in meters) of seas surrounding the Yangtze River.

Although details are lacking, their model captured the overall seasonal contributions from Yangtze River discharge to the lowest order. More details are yet to be learned from a numerical model with finer resolution and more realistic coastal features.

Although the Yangtze River discharge produces major features in the distribution of nutrients, chlorophyll and other biogeochemical properties in the ECS (e.g., Edmond et al. 1985; Gong et al. 1996; Tsunogai et al. 1999), its ability to alter circulation is rather limited. In this region, the monsoon winds, shelfward intrusion of the Kuroshio waters and northward intrusion of the Taiwan Warm Current are major forces driving the circulation. The Yangtze River is a minor force by comparison. Nevertheless, it is necessary to document possible changes 
in circulation before we address possible changes in the biogeochemistry of surrounding seas.

The East China Sea receives most of its freshwater input from the Yangtze River $\left(928 \mathrm{~km}^{3} \mathrm{yr}^{-1}\right)$. By comparison, outflows from Minjiang $\left(58.4 \mathrm{~km}^{3} \mathrm{yr}^{-1}\right)$ and Qiantangjiang $\left(35.3 \mathrm{~km}^{3} \mathrm{yr}^{-1}\right.$ ) are insignificant (Lee and Chao 2003). Dispersal of Yangtze River plume varies seasonally. Under the southerly monsoon in summer, the plume dispersal is primarily northeastward. Under the northerly monsoon in winter, the plume follows a narrow coastal jet expanding southward. With the aid of the northerly monsoon, the so-called China Coastal Current (CCC) often extends far southward into the Taiwan Strait in winter. Conceivably, the reduced Yangtze outflow after damming will weaken its northeastward dispersal in summer and southward expansion in winter. Beyond this first-order description, other possible changes of circulation in surrounding seas are not intuitively clear and require more quantitative assessment. In our view, several issues require immediate attention. One issue is the altered circulation in the semi-enclosed Yellow Sea and Bohai. The two seas are enclosed laterally and to the north; the only opening to the south borders the Yangtze River plume. It is quite conceivable that the Yangtze River plume modulates the circulation of the two seas to a certain extent. The second issue is related to the sensitivity of the China Coastal Current to the Yangtze outflow. It is known that Yangtze outflow partially feeds the CCC in winter. What would happen to the CCC if the Yangtze outflow is reduced or diminished?

\section{MODEL DESCRIPTION}

A regional ocean model for the western Pacific (Lee and Chao 2003) facilitates the present study. The model is similar to that of Semtner (1974) except with the addition of a free sea surface. The model solves for three-dimensional velocities, sea level, temperature and salinity. In addition, a passive tracer concentration equation is occasionally used in the model to illustrate the remote influence of waters in the Yellow Sea and the Bohai to the East China Sea. The computation domain (Fig. 1) extends from $23^{\circ} \mathrm{N}$ to $41^{\circ} \mathrm{N}$ and from $116^{\circ} \mathrm{E}$ to $134^{\circ} \mathrm{E}$, excluding the Sea of Japan. The horizontal resolution is $1 / 6^{\circ}$. There are 33 levels in the vertical direction. Leaving sea level fluctuations aside, the top layer is $5 \mathrm{~m}$ thick on average. Moving down the water column, the layer thickness increases at the rate of 17.65 percent per grid spacing. The maximum basin depth is therefore $6018 \mathrm{~m}$. The model resolves depth-averaged flows and sea level with a time step of $8 \mathrm{~s}$. The remaining motions, temperature, salinity and passive tracer concentration are resolved at a coarser time step of $400 \mathrm{~s}$.

The horizontal eddy viscosity is $1500 \mathrm{~m}^{2} \mathrm{~s}^{-1}$ and the horizontal eddy diffusivity for temperature and salinity is $150 \mathrm{~m}^{2} \mathrm{~s}^{-1}$. Vertical eddy viscosity and diffusivity depend on the Richardson number according to the formulation of Pacanowski and Philander (1981). Although the bottom stress is quadratic in this model, the present grid layout does not have enough vertical resolution to resolve the logarithmic bottom friction layer with a thickness of $1 \mathrm{~m}$ or so. Since our bottom layer is much thicker than $1 \mathrm{~m}$, the preliminary model tuning produced much better agreement with observations if the bottom drag is reduced. For this reason, the dimensionless bottom drag coefficient is chosen to be a very small value $\left(C_{d}=0.000054\right)$. This bottom drag reduction leads to much better agreement with observa- 
tions than previously reported in Lee and Chao (2003).

The modeled ocean is initially motionless, with prescribed distributions of January climatological temperature and salinity fields (Levitus and Boyer 1994). The ocean is forced by the monthly climatological wind stress of Hellerman and Rosenstein (1983). More recent wind products such as COADS are not used because, drawing from our own experience, they do not improve the simulated ocean circulation if one is only interested in monthly climatology. Following Sarmiento and Bryan (1982), the modeled temperature and salinity are weakly nudged toward monthly climatological values given by Levitus and Boyer (1994). Let $\theta$ be either temperature or salinity. The conservation equation for $\theta$ becomes $D \theta / D t=$ mixing $+\gamma\left(\theta^{*}-\theta\right)$, where $D / D t$ is the substantial differential operator in three dimensions and $\theta *$ is the climatological field. The restoration rate $(\gamma)$ is 0.02 day $^{-1}$ in the top $50 \mathrm{~m}$ of the ocean, zero between $50 \mathrm{~m}$ and $870 \mathrm{~m}$, and 0.008 day $^{-1}$ below $870 \mathrm{~m}$ depth. The complete removal of nudging at intermediate depths is meant to allow the baroclinic density structure associated with the Kuroshio Current to move more freely. It should also be noted that $\gamma$ is sufficiently small over the shelf such that simulated temperature and salinity fields deviate considerably from climatology. Since salinity and temperature fields are nudged, heat and salinity fluxes are set to zero at the sea surface.

Inflows and outflows through open ocean boundaries are specified at their climatological positions. In imposing inflows and outflows, the depth-integrated currents were specified on open boundaries, but deviations from the depth averages were extrapolated from adjacent interior values through radiation conditions. The inflow water was given the climatological temperature and salinity values. For outflows, temperature and salinity on open boundaries are determined by advection. Figure 2a shows the model-prescribed monthly volume transports for the northward Kuroshio inflow from east of Taiwan, eastward Kuroshio outflow to the south of Japan, northward inflow from the Taiwan Strait, and northward outflow through the Tsushima Strait. Justifications for the choice of monthly transport values were given in Lee and Chao (2003).

Figure $2 \mathrm{~b}$ shows monthly discharge from the Yangtze River compiled by the Global Runoff Data Center of the Federal Institute of Hydrology in Germany (http://www.bafg.de/ grdc.htm). The discharge peaks in July and decreases thereafter to a minimum in January. Model sensitivity to Yangtze outflow is explored by reducing the monthly Yangtze discharge rate proportionally while retaining its seasonality. In the four experiments as listed in Table 1, the monthly Yangtze River discharge is fully implemented in experiment A but completely eliminated in experiment $\mathrm{D}$. It is reduced by 10 percent in experiment $\mathrm{B}$ and 70 percent in experiment C. According to the box model of Chen (2000), a 10 percent reduction seems to be a threshold over which visible changes in the ECS begin to occur. On the other hand, a 70 percent discharge reduction is not uncommon for dam constructions elsewhere, such as the Farakka Dam on the Ganges River in India.

The Yangtze River discharge has often been regarded as the dominant freshening source of the southern East China Sea. The potential contribution from the Bohai and Yellow Seas has been either underappreciated or ignored so far. To highlight this northern contribution in experiment A, we have added a passive tracer in the Bohai and Yellow Seas. The passive tracer is subject to advection and mixing in three dimensions. The vertical diffusion is the 
(a)
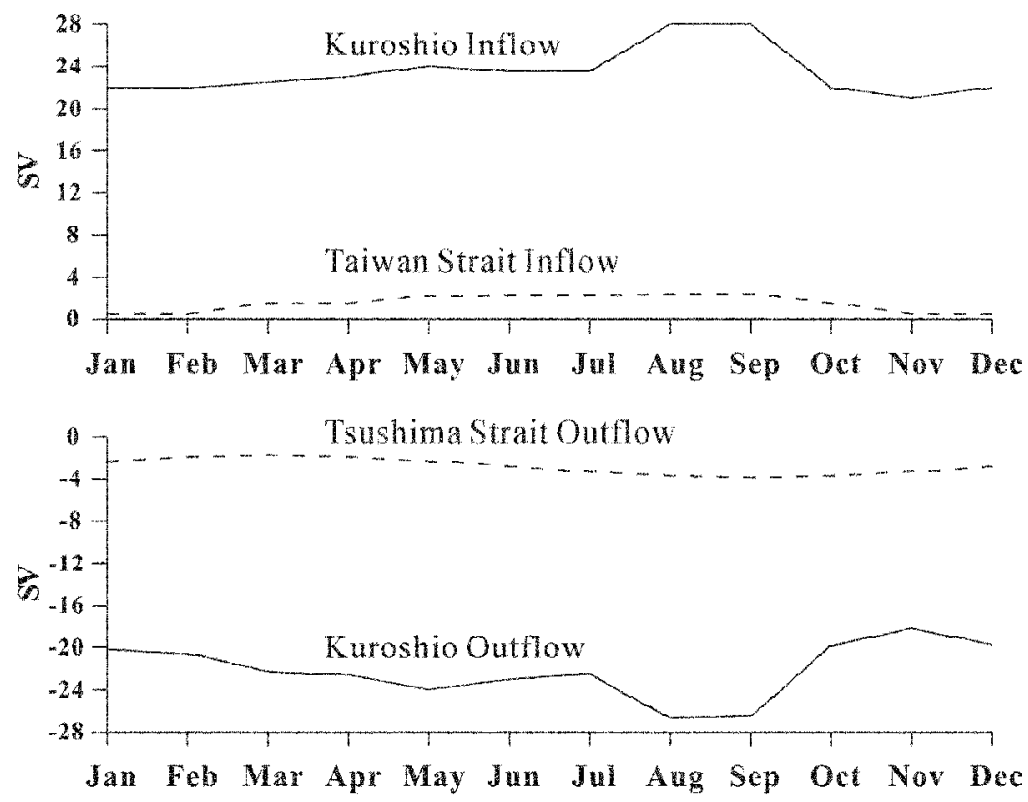

(b)

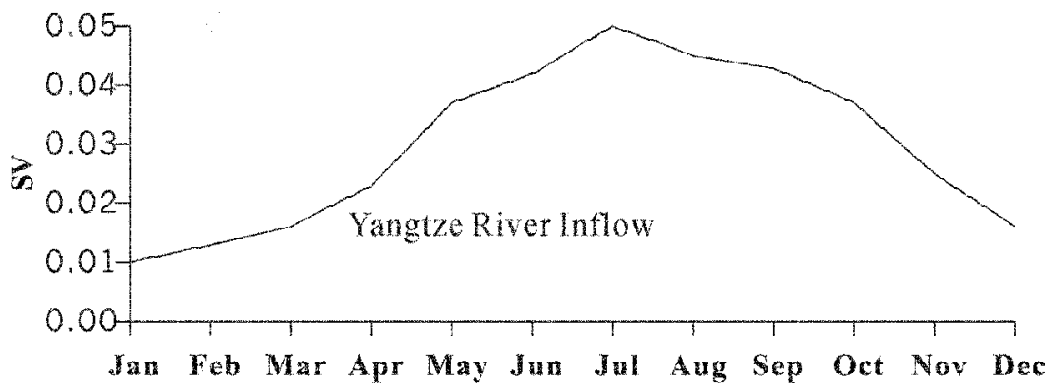

Fig. 2. Monthly volumetric fluxes of (a) inflows (upper panel) and outflows (lower panel) through open ocean boundaries, and (b) Yangtze River discharge imposed on the model.

same as in the salinity or temperature equation. The horizontal mixing coefficient is $1500 \mathrm{~m}^{2} \mathrm{~s}^{-1}$. The tracer concentration is initially 100 north of $35^{\circ} \mathrm{N}$ and zero elsewhere. Subsequent tracer dispersion will be examined. 
Table 1. List of experiments:

\begin{tabular}{ccc}
\hline Experiments & Yangtze Discharge & Tracer \\
\hline $\mathrm{A}$ & Normal & Yes \\
$\mathrm{B}$ & $10 \%$ reduction & No \\
$\mathrm{C}$ & $70 \%$ reduction & No \\
$\mathrm{D}$ & Closed & No
\end{tabular}

\section{CIRCULATION FEATURES WITH NORMAL YANGTZE RIVER DISCHANGE}

The model is spun up from the initially motionless state for three years. Having reached a quasi-steady annual cycle, the third year's result from experiment $\mathrm{A}$ is discussed below. In terms of model-data agreement, features discussed herein present a major improvement over the previous model result of Lee and Chao (2003). The improvement arises mostly from the much reduced bottom drag coefficient.

Figure 3 shows the depth-averaged surface circulation in (a) July and (b) December. The depth average is over the top $830 \mathrm{~m}$ of the ocean. If the local water depth is shallower than $830 \mathrm{~m}$, the depth average is over the entire water column. Major features are noted below. East of the island of Taiwan, the northward Kuroshio Current enters the East China Sea and forms an anticyclonic meander off northeast Taiwan. Farther northeast of Taiwan, the Kuroshio begins to follow the shelf break northeastward. Approaching the island of Kyushu, the Kuroshio once again forms an anticyclonic meander to the southwest of Kyushu. Near the southern tip of Kyushu, the Kuroshio leaves the East China Sea through the Tokara Straits. Thereafter it follows the southern coast of Japan to the northeast. The Kuroshio path along the shelf break of the East China Sea is generally quite steady except for the two anticyclonic meanders. Seasonal variations of the two meanders have been discussed in Lee and Chao (2003) and will not be reiterated here.

The winter appearance of the Yellow Sea Warm Current (YSWC) is consistent with the schematic circulation pattern as envisioned by Su (1998). The branching off of the shelfward current southwest of Kyushu also agrees quite well with the flow paths in the northeastern ECS for the cold season derived from drifter trajectories by Lie et al. (1998). As is shown in Fig. $3 \mathrm{~b}$, the northward YSWC enters the Yellow Sea as a narrow current along the deep reaches between the China continent and Korea Peninsula. Approaching the Shandong Peninsula, the YSWC bifurcates. The eastern branch returns southward along the west coast of the Korean Peninsula; this is sometimes referred to as the Korean Coastal Current (KCC). The western branch returns southward along the southern coast of Shandong Peninsula, forming the socalled Yellow Sea Coastal Current (YSCC) which is the beginning of the CCC. As noted by 
(a)

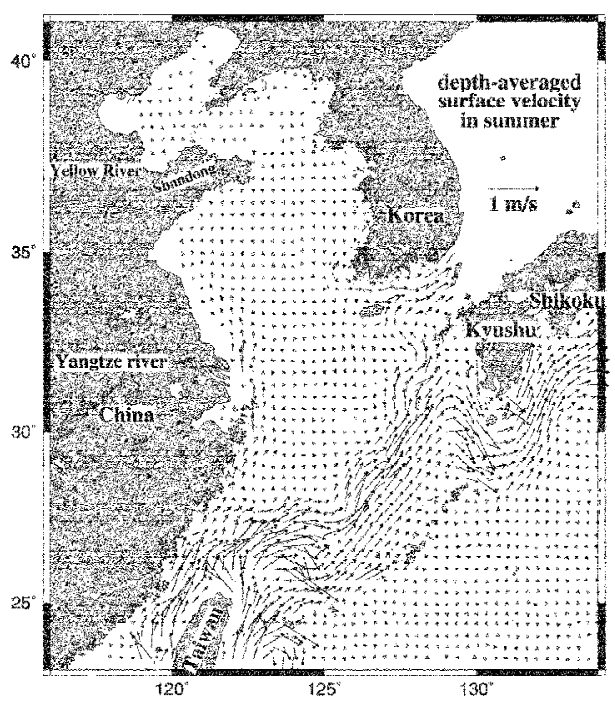

(b)

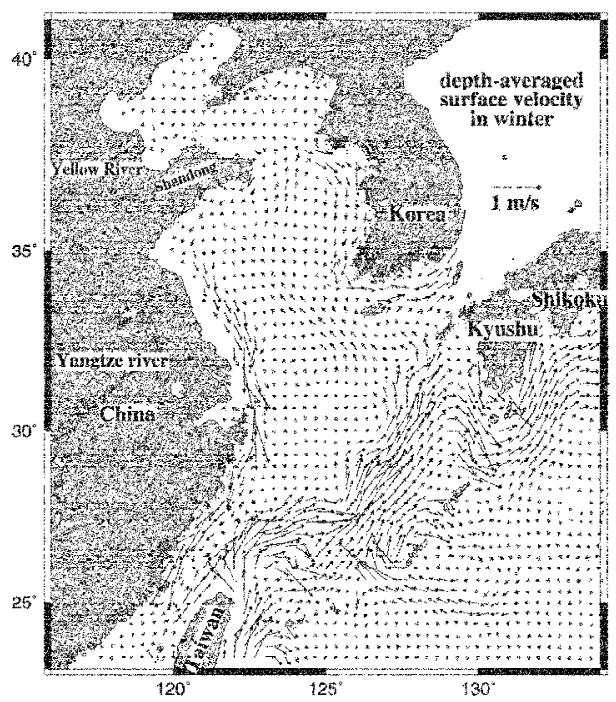

Fig. 3. Depth-averaged surface circulation in (a) July and (b) December derived from experiment A, in which the normal level of Yangtze River discharge is imposed. The depth average is over the top $830 \mathrm{~m}$ or entire water column, whichever is shallower.

Su (1998) and in recent numerical studies (Mask et al. 1998; Naimie et al. 2001), the winter current system in the Yellow Sea is mostly driven by local northwesterly winds. The strong northwesterly winds drive southward the KCC and the YSCC on both sides of Yellow Sea, demanding a northward return flow (YSWC) in between. It is noted that the climatological monthly wind field used in this simulation precludes the occurrence of an intermittent YSWC probably generated by fluctuating monsoonal forcing as proposed by Lie et al. (2001). However, the path of the modeled YSWC agrees very well with the mean position of the warm tongue revealed by the infrared imagery from the NOAA satellite (Lie et al. 2001).

Another noteworthy feature in winter (Fig. 3b) is the generally southward coastal jet (or CCC) extending from south of Shandong Peninsula to well into the Taiwan Strait. The northern segment of this coastal current in the Yellow Sea is often referred to as the YSCC (Yellow Sea Coastal Current) instead. This coastal jet is largely driven by the northerly monsoon in winter. The Yangtze River discharge may also contribute to it; this point will be elaborated in later sections. The year-round northward current entering the East China Sea from the Taiwan Strait is also noteworthy. This current is generally warm and saline, and hence often referred to as the Taiwan Warm Current.

In summer, the sea surface temperature (SST) is nearly isothermal or featureless in the vicinity of the Yangtze plume, and therefore will not be shown here. In winter, strong and sinuous frontal features develop off the Yangtze River. Figure 4a shows a typical satellite- 
derived SST field in winter (December 1999). The confluence of cold waters from the Yellow Sea and warm waters from the south leads to a meander front off the Yangtze River mouth. The front is generally oriented in the southwest-northeast direction. An area of enhanced frontal mixing develops between the Yangtze River mouth and the southern tip of the Korean Peninsula, leading to a southward excursion of the front. South of the Yangtze River mouth, cold waters intrude southward to form a narrow band along the China coastline. The modelproduced SST field in December (Fig. 4b) is similar. Following the $18^{\circ} \mathrm{C}$ isotherm, for example, one sees degradation of the north-south temperature gradient (and hence enhanced mixing) off the Yangtze River mouth. The southward excursion of an $18^{\circ} \mathrm{C}$ isotherm between the Yangtze River mouth and the southern tip of Korean Peninsula is consistent with the satellite-derived SST field (Fig. 4a). The narrow coastal band of cold waters south of the Yangtze River mouth is also consistent with the satellite image.

To lend more credibility to the model, the depth-averaged surface circulation for December is superimposed on the satellite-derived mean SST for December in Fig. 5. The satellitederived SST is an average of all December archives from 1999 to 2001 and therefore represents the climatological winter SST in the region to a degree. The agreement is apparent, as currents closely follow isotherms in most places.

Figure 6 shows observation-based sea surface salinity (SSS) fields in summer (left panels) and winter (right panels). Climatological SSS fields in summer (Fig. 6a) and winter (Fig. 6b) derived from National Oceanic Data Center (NODC) are limited by coarse $\left(1^{\circ}\right)$ resolution.

(a)

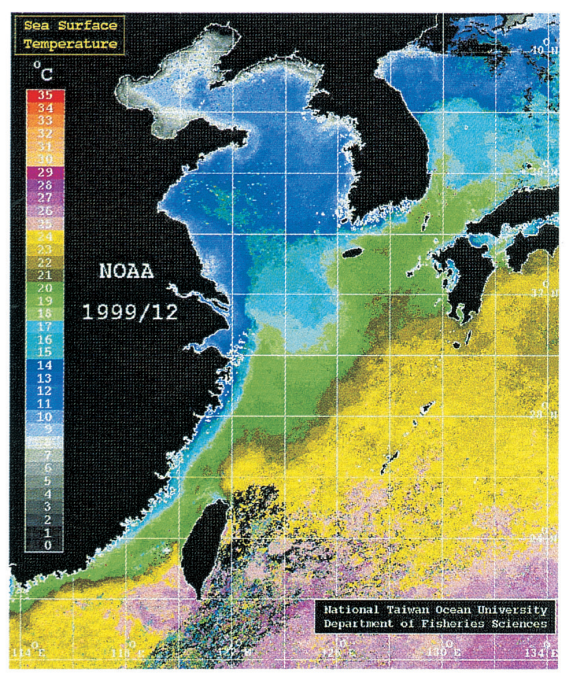

(b)

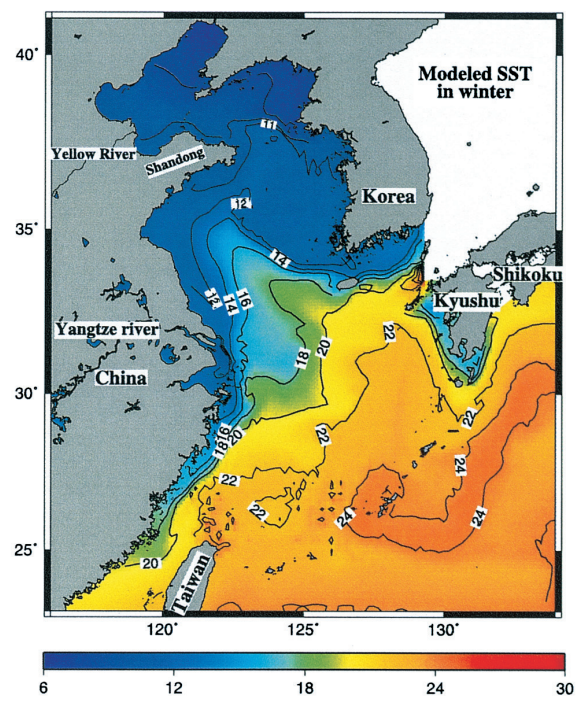

Fig. 4. December sea surface temperature derived from (a) satellite image in 1999 and (b) experiment A with normal level of Yangtze River discharge. 


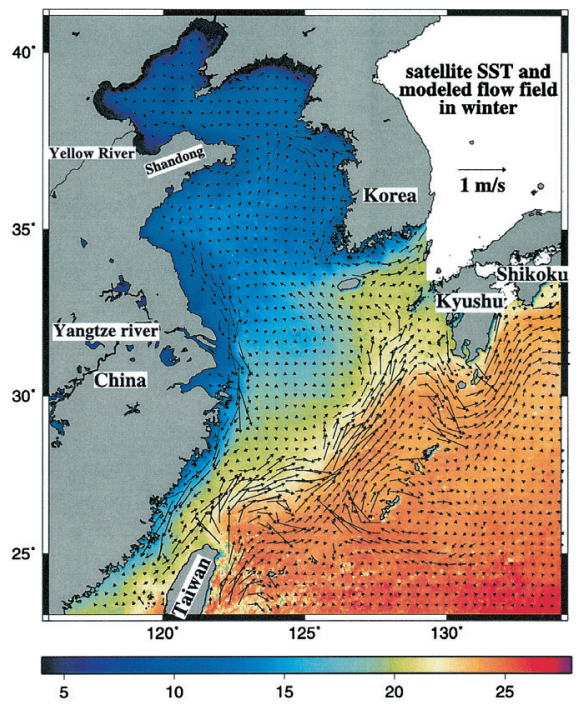

Fig. 5. Depth-averaged surface circulation in December derived from experiment A, superimposed on the mean sea surface temperature derived from satellite images for December. The satellite-derived SST is an average of all December archives from 1999 to 2001. The depth average is over the top $830 \mathrm{~m}$ or entire water column, whichever is shallower.

Nevertheless, the signature of the Yangtze River plume is unmistakable in summer, spreading out toward the northeast. Climatological SSS contours in winter are oriented southwestnortheast; the resolution is too coarse to resolve the China Coastal Current to the south of the Yangtze River mouth. To compensate for the deficiency, ship-surveyed SSS fields from Gong et al. (2003) are shown for summer of 1998 (Fig. 6c) and winter of 1997 (Fig. 6d) to the south of the Yangtze River mouth. With enhanced resolution, the southward intrusion of fresher water along the China coastline becomes evident in winter, as indicated by $32 \sim 33$ isohalines in Fig. 6d.

The model-derived SSS fields (Fig. 7) capture major features revealed from observations. In July (Fig. 7a), the over-bloated Yangtze River plume expands from the river mouth to the northeast. Some of the low salinity waters manage to leak into the Sea of Japan through the Tsushima Strait. The dispersion agrees with that revealed in climatological SSS (Fig. 6a). In December (Fig. 7b), the Yangtze outflow hugs the China coastline and penetrates southward. The movement is consistent with the ship-derived SSS (Fig. 6d). The model-produced SSS in the winter Yellow Sea contains additional features that are not resolved in climatological SSS. The northward intrusion of saline waters into the Yellow Sea (Fig. 7b), apparently induced by the Yellow Sea Warm Current, is conspicuously missing in climatological SSS (Fig. 6b). Our salinity nudging rate is quite weak $\left(0.02\right.$ day $\left.^{-1}\right)$ over the continental shelf and therefore allows the modeled salinity field to deviate markedly from climatological SSS fields. 
(a)

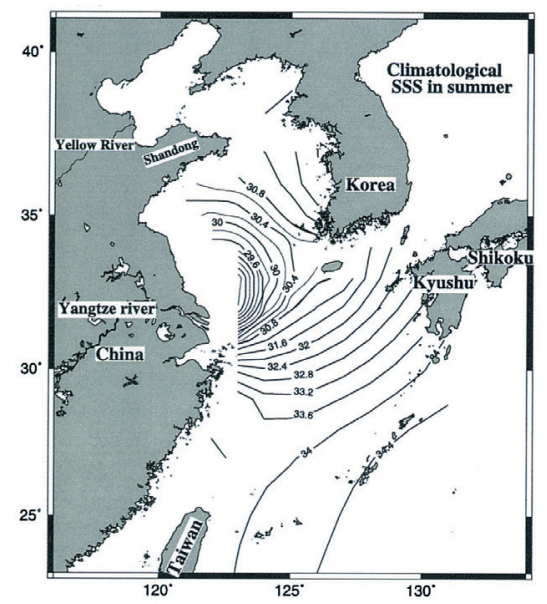

(c)

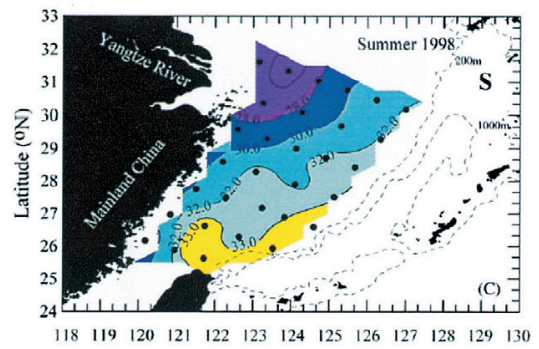

(b)

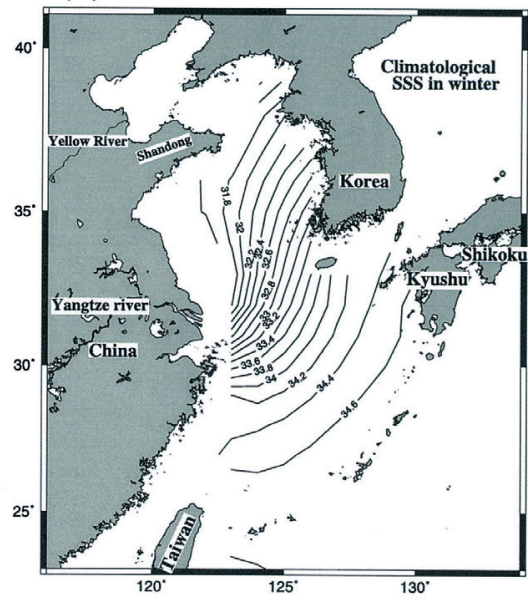

(d)

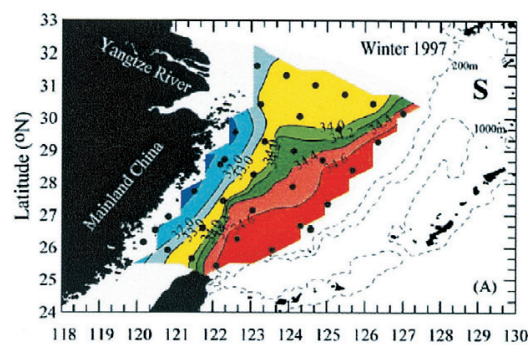

Fig. 6. Sea surface salinity fields derived from (a) NODC climatology in summer, (b) NODC climatology in winter, (c) ship measurement in summer of 1998, and (d) ship measurement in winter of 1997.

\section{REDUCED YANGTZE OUTFLOW}

The Yangtze River discharge is 90 percent of the normal level in experiment B, 30 percent of the normal level in experiment $\mathrm{C}$, and completely terminated in experiment $\mathrm{D}$. Since salinity is the best indicator of the changes brought about by the Yangtze outflow, the discharge reduction scenarios are illustrated below by model-produced SSS.

Figure 8 shows modeled SSS for experiment B in (a) July and (b) December. In this case the Yangtze outflow reduction is only 10 percent. The resulting SSS fields are visually indistinguishable from that under normal discharge (Fig. 7).

Visible differences emerge with a 70 percent reduction of the Yangtze River outflow (Fig. 9). In summer (Fig. 9a), the Yangtze River plume to the northeast of the river mouth is visibly 
(a)

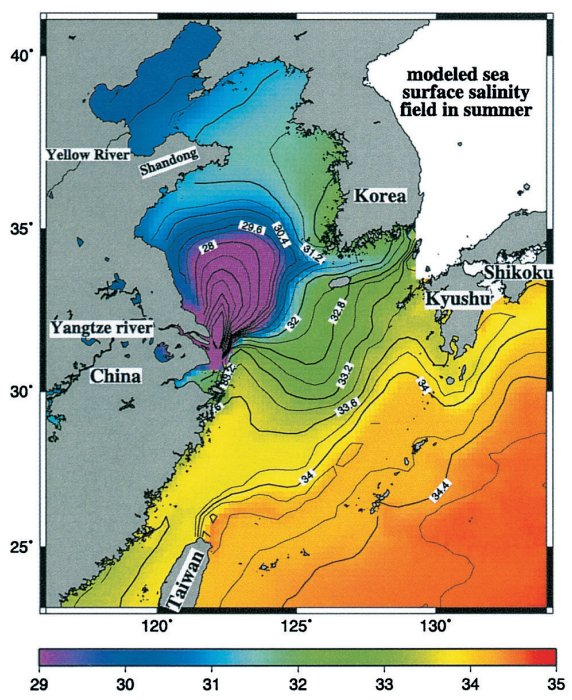

(b)

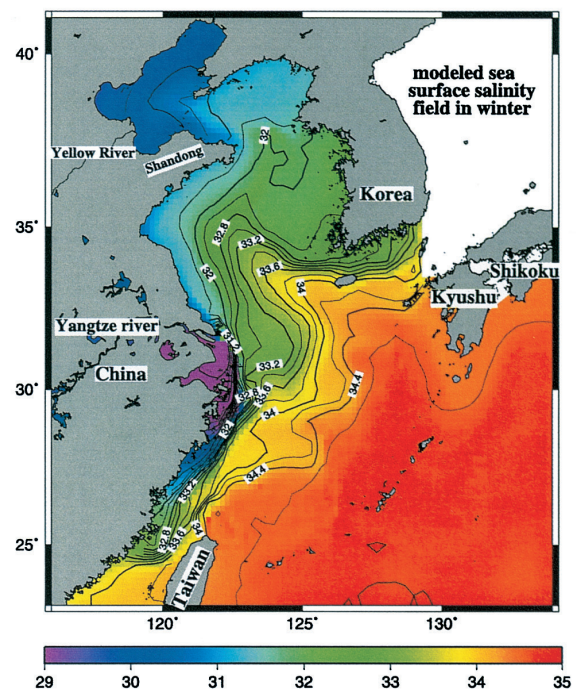

Fig. 7. Sea surface salinity fields in (a) July and (b) December derived from experiment A with normal level of Yangtze River discharge.

(a)

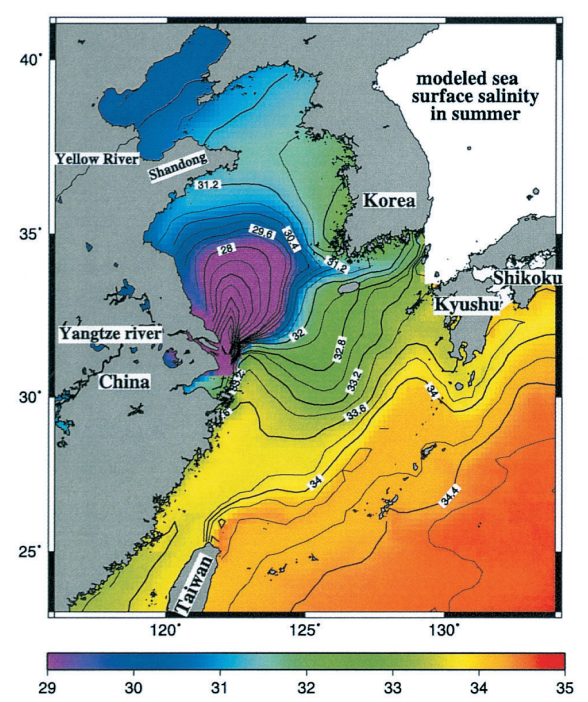

(b)

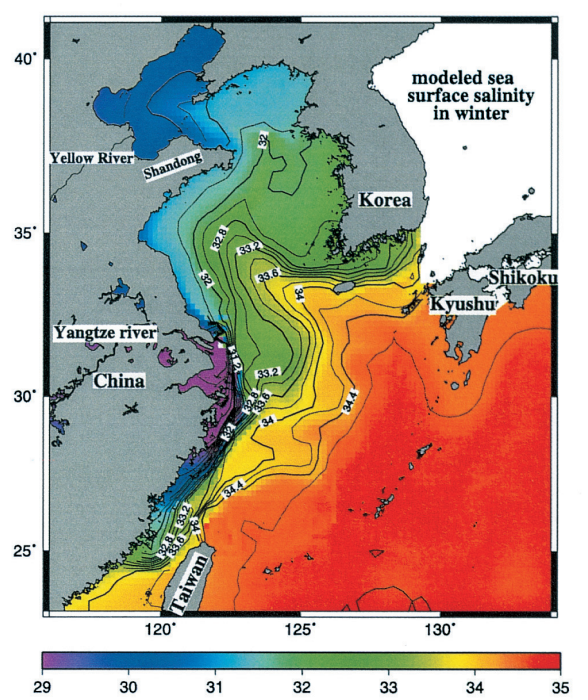

Fig. 8. Sea surface salinity fields in (a) July and (b) December derived from experiment $\mathrm{B}$, in which the monthly Yangtze River discharge is reduced by 10 percent. 
(a)

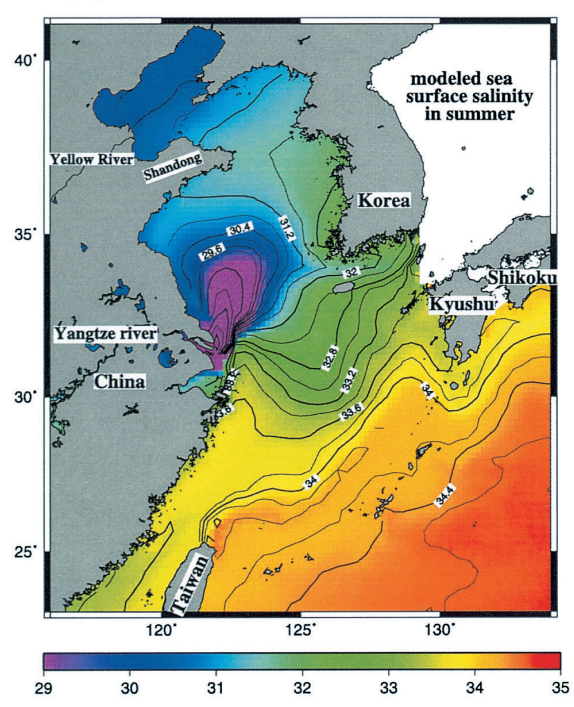

(b)

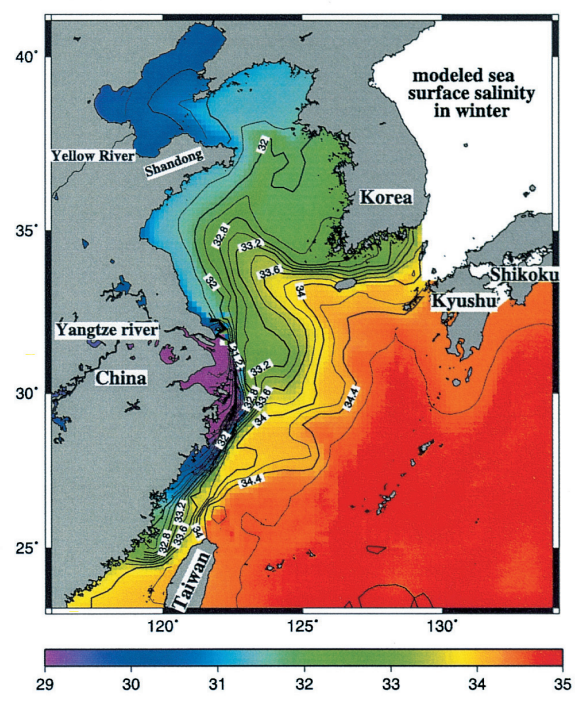

Fig. 9. Sea surface salinity fields in (a) July and (b) December derived from experiment $\mathrm{C}$, in which the monthly Yangtze River discharge is reduced by 70 percent.

reduced in size. Nevertheless, some of the low salinity waters still leak out through the Tsushima Strait to the Sea of Japan. In winter (Fig. 9b), the amount of fresher water is visibly reduced near the Yangtze River mouth. For example, the southward expansion of waters with salinity lower than 30 psu is visibly reduced. For waters with slightly higher salinity (32.8 psu, for example), the southward penetration along the China coastline is not visibly diminished, extending well into the Taiwan Strait as in previous experiments (Fig. 7b or Fig. 8b). Thus, the effect of reduced Yangtze River discharge on the plume dispersal appears to be more profound in summer than in winter. While the summer northeastward dispersal is visibly reduced in response to the reduced outflow, the winter southward expansion is relatively unimpeded by the reduced outflow. Reasons will be given in the next section, in which passive tracer will be deployed to examine the exchange between Yellow and East China Seas.

Figure 10 shows modeled SSS fields if the Yangtze outflow is completely terminated. The summer plume to the northeast of Yangtze River mouth disappears (Fig. 10a). The ambient SSS field remains very similar to that with normal Yangtze River outflow (Fig. 7a). In winter (Fig. 10b), however, the CCC still carries colder and fresher water from the Yellow Sea southward, extending well into the Taiwan Strait. Waters carried by the CCC become more saline in the absence of the Yangtze River outflow. To quantify better, the termination of the Yangtze River reduces the southward penetration of 32.8 psu isohaline by about 2 degrees in latitude.

Figure 11 shows SSS anomalies if the Yangtze River discharge is reduced by 10 percent (top panels) or 70 percent (bottom panels). Left panels (Figs. 11a, c) are for July while right 
(a)

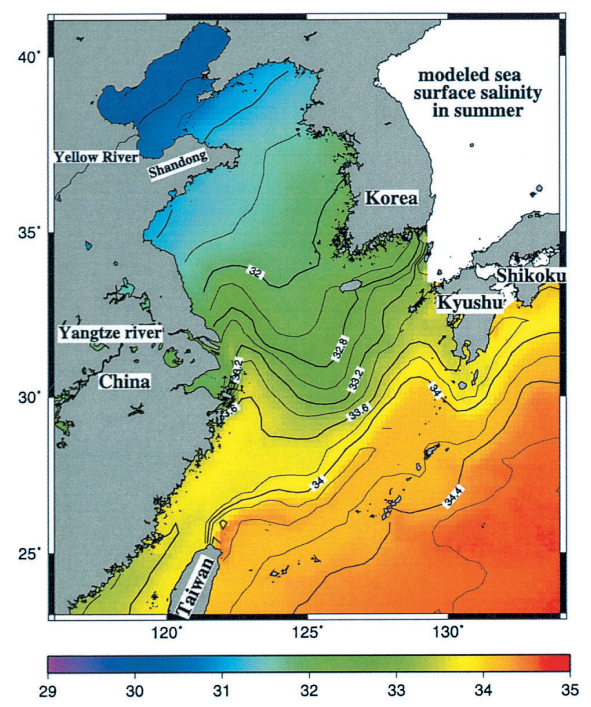

(b)

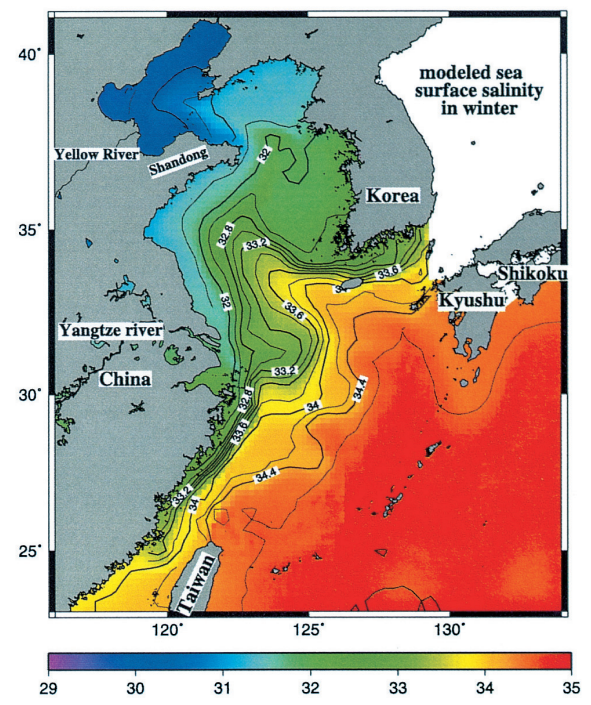

Fig. 10. Sea surface salinity fields in (a) July and (b) December derived from experiment $\mathrm{D}$, in which the monthly Yangtze River discharge is completely eliminated.

panels (Figs. 11b, d) are for December. Even with only a 10 percent outflow reduction, changes in SSS fields are quite visible especially in summer. The summer plume to the northeast the Yangtze River mouth gains SSS anomalies ranging up to 1 psu or more (Fig. 11a) due to the weaker outflow. Further, the summer SSS anomaly extends well into the Tsushima Strait, indicating that less brackish water is available for export to the Sea of Japan if the Yangtze River discharge is reduced. The winter coastal jet to the south of the Yangtze River mouth gains SSS anomalies up to 0.25 psu, which is considerably less than the summer SSS anomalies to the northeast of the Yangtze River mouth.

The SSS anomalies increase markedly if the Yangtze outflow is reduced by 70 percent. Summer anomalies (Fig. 11c) range up to 10 psu to the northeast of the Yangtze River mouth, while the maximum winter anomaly (Fig. 11d) can be up to 1 psu right off the Yangtze River mouth. A summer deficit of 10 psu induced by a 70 percent outflow reduction (Fig. 11c) is quite consistent with observed salinity changes in 1998 and 1999 (Delcroix and Murtugudde 2002; Fig. 5). The winter SSS anomaly extends well into the Taiwan Strait and then returns northeastward to the southern East China Sea, apparently being advected by the northeastward Taiwan Warm Current.

Flow fields from experiment D (without Yangtze outflow) can be subtracted from that from experiment A (with normal Yangtze outflow) to deduce circulation contributed by the Yangtze River discharge alone. Figure 12 shows close-up views of the circulation anomalies 
(a)

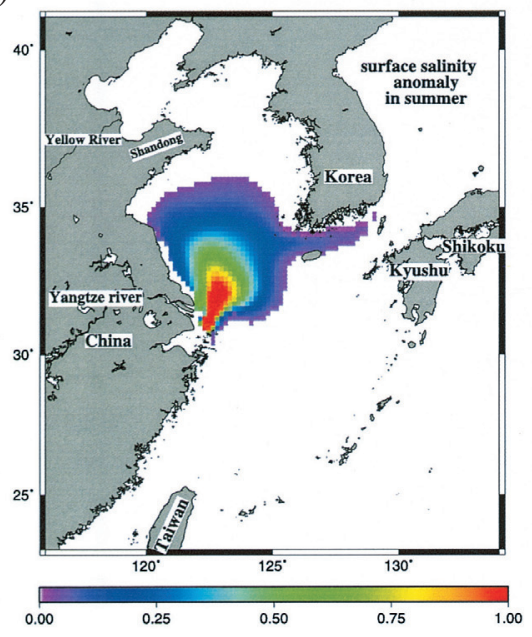

(c)

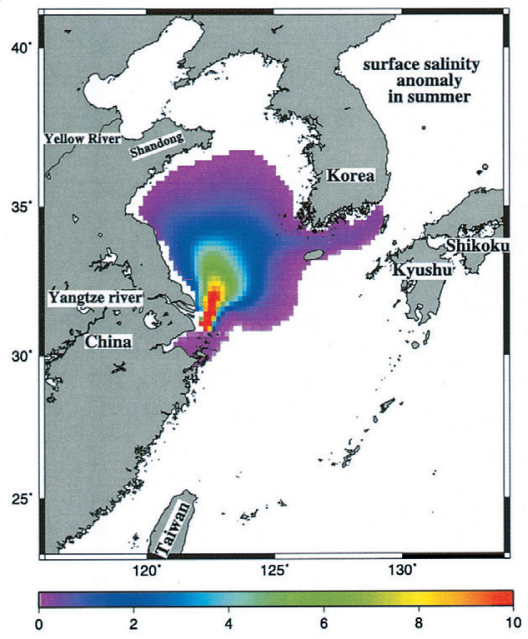

(b)

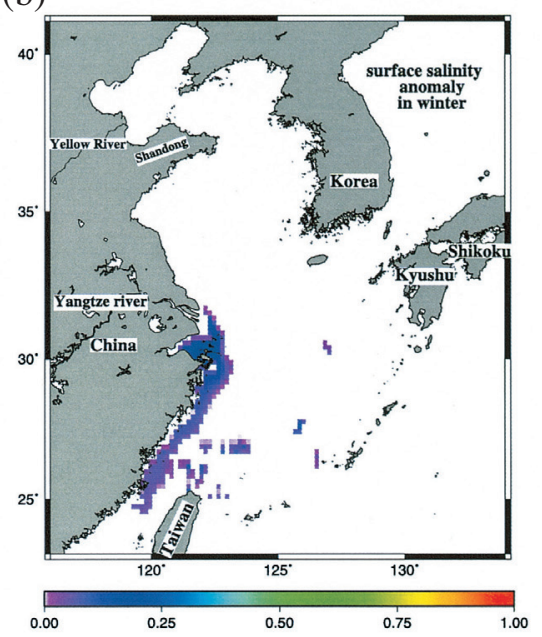

(d)

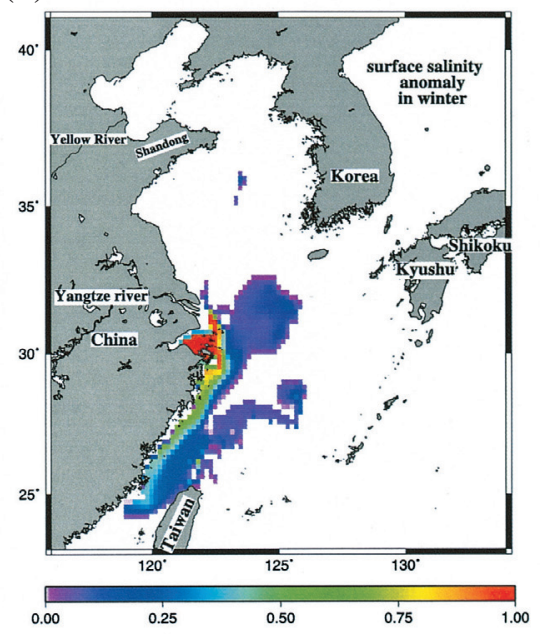

Fig. 11. Positive anomalies of sea surface salinity induced by reductions of Yangtze River discharge. Top panels are differences between experiments A and $\mathrm{B}$ in (a) July and (b) December, resulting from 10 percent decrease of discharge. Bottom panels are corresponding differences between experiments $\mathrm{A}$ and $\mathrm{C}$, resulting from 70 percent outflow reduction.

in summer (left panels) and winter (right panels). Since the anomaly contains a strong baroclinic component, top panels show flow anomalies at the sea surface while bottom panels show depth-averaged flow anomalies. In summer, the Yangtze River outflow induces an anticyclonic surface circulation to the northeast of the river mouth (Fig. 12a). The shoreward (western) 
side of the anticyclone is largely barotropic. The seaward (eastern) side is strongly baroclinic with a southward surface flow and a northward bottom current. In consequence, the depthaveraged flow is quite weak in the eastern half of the anticyclone (Fig. 12c). The Yangtze River discharge also induces a southward coastal current to the south of the river mouth in summer. This southward coastal current is largely barotropic and is made visible only because the northward ambient current is removed. Recall that the coastal current to the south of the Yangtze River mouth is northward in summer (Fig. 3a). Figures 12a and c suggest that the summer Yangtze River plume weakens the northward coastal current from the south.

(a)

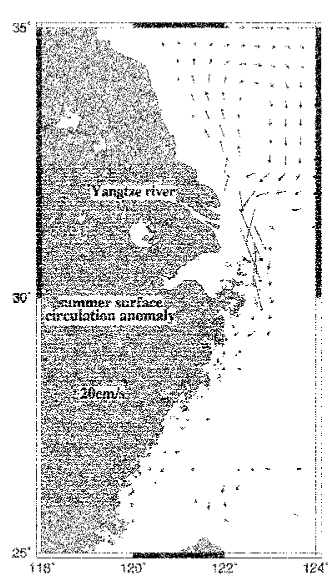

(c)

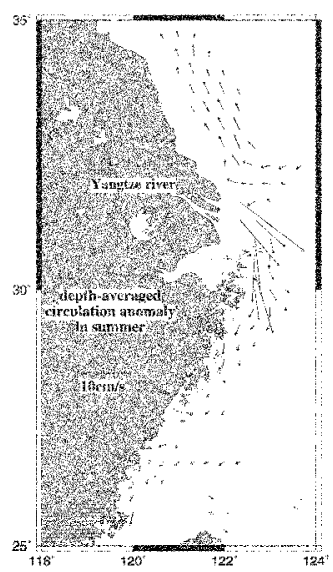

(b)

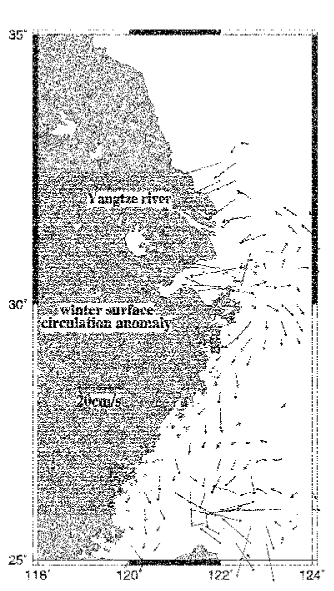

(d)

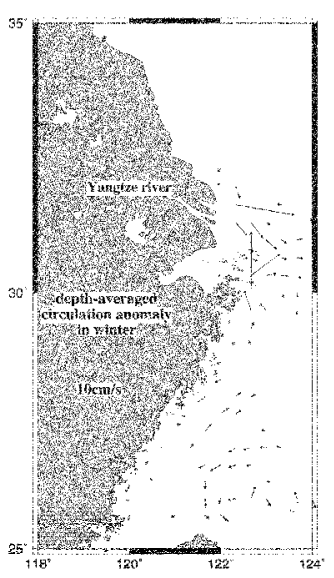

Fig. 12. Close-up views of anomalous flow fields induced by Yangtze River discharge alone. The flow fields are the difference between experiment A (with normal discharge) and experiment $\mathrm{D}$ (without discharge). Top panels are surface anomalies in (a) July and (b) December. Bottom panels are depth-averaged anomalies in (c) July and (d) December. 
Delcroix and Murtugudde (2002) also deduced the sea surface circulation anomalies induced by the Yangtze River outflow from their model for August 1998. In their model the Yangtze River outflow supports an expansive anticyclonic surface circulation confined between $28 \mathrm{~N}$ and $35 \mathrm{~N}$ (see their Fig. 14). Our model suggests a much narrower anticyclonic circulation anomaly in summer, confined mostly between $32 \mathrm{~N}$ and $35 \mathrm{~N}$ (Fig. 12a). The improved horizontal resolution and explicit inclusion of coastal areas shallower than $40 \mathrm{~m}$ in the present model are apparently responsible for the difference.

The winter flow anomaly induced by the Yangtze River forcing extends mostly from the river mouth to the south. Off the river mouth, the Yangtze discharge induces dipolar vortices, circulation being cyclonic in the northern portion and anticyclonic in the southern portion of the dipole (Figs. 12b and d). Farther southward, the Yangtze River's contribution to the winter CCC is largely baroclinic, consisting of a surface southward flow and a bottom northward flow. In consequence, the depth-averaged coastal current is either weakly southward or nearly zero far south of the Yangtze River mouth (Fig. 12d). Recall that the winter CCC is mostly barotropic (Fig. 3b). The barotropic nature of the $\mathrm{CCC}$ is mainly caused by downwellingfavorable winds in winter. Excluding wind forcing, the river forcing induces a baroclinic flow structure in the far field. The Yangtze River forcing also induces substantial flow fields off the northern tip of Taiwan, currents being eastward (seaward) off northern Taiwan and westward (landward) slightly to the north. Leaving the ambient flow field aside, the eastward flow off northern Taiwan provides impetus for fresher water coming out of the Taiwan Strait to move seaward. The westward flow anomaly farther off the northern tip of Taiwan appears to be a return flow to compensate for the seaward flow to the south of it.

\section{DISPERSAL OF YELLOW SEA AND BOHAI WATER}

The preceding experiments shed some light on the relationship between the winter appearance of the CCC and the Yangtze River outflow. If the Yangtze River outflow is terminated or severely weakened, the CCC will carry Yellow Sea water and, to a less extent, Bohai water southward. What is unclear from the preceding results is whether Yangtze River water and Yellow Sea water are mutually exclusive in the CCC. Theoretically speaking, a river plume is separated from the ambient sea by a density front, which is a dynamical barrier against cross-frontal exchange of waters and waterborne materials. If the Yangtze River discharge is the only source water feeding the $\mathrm{CCC}$, there is a possibility that the front developed between Yangtze River water and East China Sea water will prohibit entrainment of Yellow Sea water into the CCC. To address this issue, a passive tracer is added to experiment A, in which the full level of Yangtze River discharge is implemented. The passive tracer is not implemented for the first year of simulation. After the initial spin-up for a year, the tracer is suddenly imposed at the beginning of the second year and thereafter allowed to disperse freely. Initially, the passive tracer of 100 units in concentration is uniformly distributed in the semienclosed basin north of $35^{\circ} \mathrm{N}$, covering both the Yellow Sea and the Bohai. Subsequent dispersion is tracked for two years.

Figure 13 shows the sea surface tracer concentration in (a) July and (b) December of the 
(a)

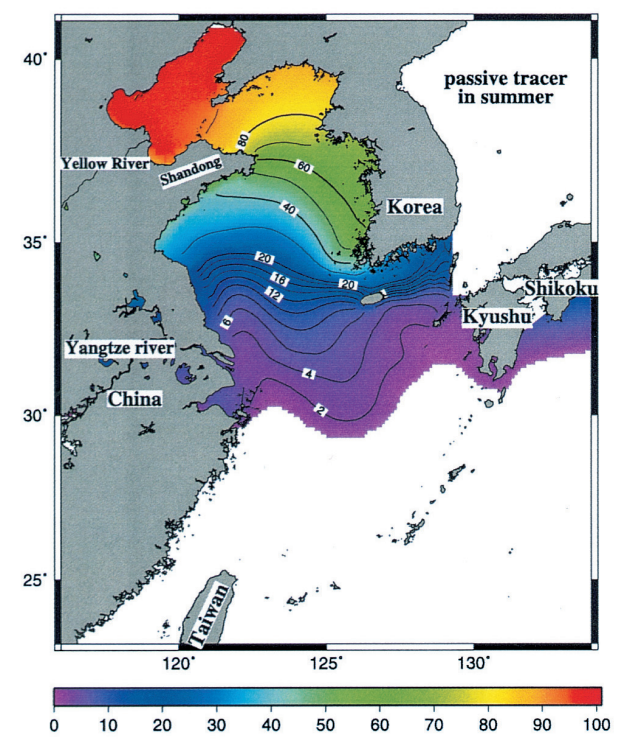

(b)

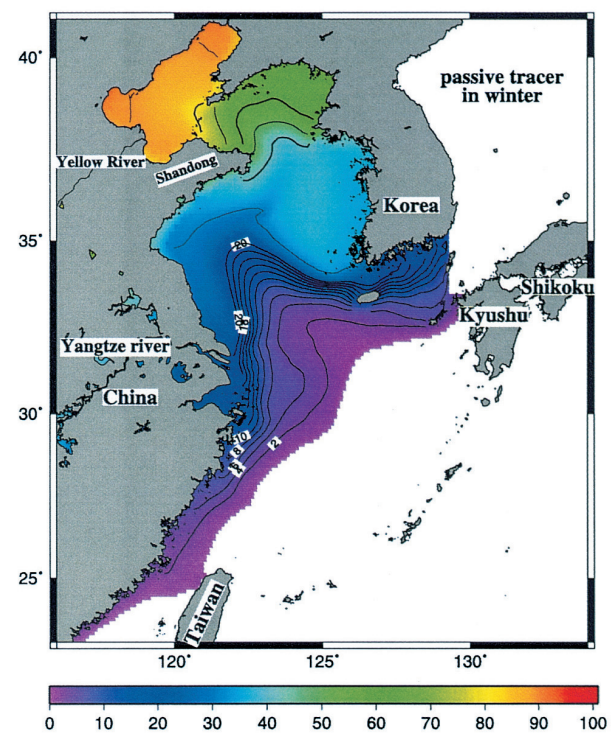

Fig. 13. Surface distributions of tracer concentrations at $2.5 \mathrm{~m}$ depth below sea surface in (a) July and (b) December of the first year after tracer release. The initial tracer is uniformly distributed in the Yellow Sea and Bohai with a concentration of 100 units north of $35^{\circ} \mathrm{N}$. The flow fields driving the tracer movements are from experiment A with normal Yangtze River discharge.

first year after the sudden imposition of the passive tracer. Distributions for the second year are similar except the concentration becomes much weaker, and therefore will not be shown. In general, the tracer distributions resemble SSS distributions in the absence of Yangtze River discharge (Fig. 10). The tracer concentration is the highest in the Bohai, suggesting a much slower flushing rate in the Bohai than in the Yellow Sea. Some of the tracer concentrations slowly leak out through the Tsushima Strait; this eastward leakage is a year-round feature which lacks strong seasonality. In contrast, the southward dispersion contains a distinct seasonal variation. In summer, the southerly monsoon blocks the southward dispersion of tracer. In winter, the southward tracer dispersion is aided by the northerly monsoon, following the CCC southward. Note that the tracer is released in conjunction with normal levels of Yangtze River discharge in the experiment (experiment A). In other words, source waters in the winter CCC come partly from the Yangtze River discharge and partly from the Yellow Sea.

Figure 14 shows the percentage leakage rate of the total tracer concentration over the entire semi-enclosed basin north of $35^{\circ} \mathrm{N}$ as a function of time for the two years after the tracer release. Let $\mathrm{C}(\mathrm{t})$ be the total tracer concentration north of $35^{\circ} \mathrm{N}$ at a given time $(\mathrm{t})$. The percent- 
age leakage rate is given by $[\mathrm{dC}(\mathrm{t}) / \mathrm{dt}] / \mathrm{C}(\mathrm{t})$, where $\mathrm{t}$ is expressed in units of years. There is interannual variability in this time series because the tracer concentration decreases indefinitely after initialization. Leaving interannual variations aside, there is a strong annual cycle in the flushing rate of the Yellow Sea and Bohai. The leakage rate is at a maximum around the end of November and a minimum around the end of May. The summer minimum is apparently due to blocking by the southerly monsoon. As we illustrated in Fig. 13a, the summer monsoon prevents tracer concentrations from expanding southward. The November-December maximum is mostly caused by the enhanced northerly monsoon and consequent development of the CCC, which carries tracer southward along the China coastline (Fig. 13b).

More quantitatively, the average tracer concentration north of $35^{\circ} \mathrm{N}$ decreases continuously from the initial value of 100 to 39.5 at the end of first year and then to 18.6 at the end of second year, suggesting a flushing rate of about 60 percent per year in the Yellow Sea and Bohai. This implies a mean residence time of about $1.7 \mathrm{yr}$ for the Yellow Sea-Bohai water. The quantitative estimate should be taken with a little caution. Horizontal mixing in general circulation models is generally greater than that in the real ocean and therefore introduces some uncertainties in quantifying flushing rates. Even so, a box model for salt and water balance (Liu and Chen 2002) has suggested a comparable residence time (1.4 yr) for the northern ECS north of the Yangtze River mouth plus the Yellow Sea-Bohai basin. Leaving the quantitative estimate aside, the seasonal variation of the flushing rate is much more reliable because it is directly related to circulation features that are not easily overcome by horizontal mixing.

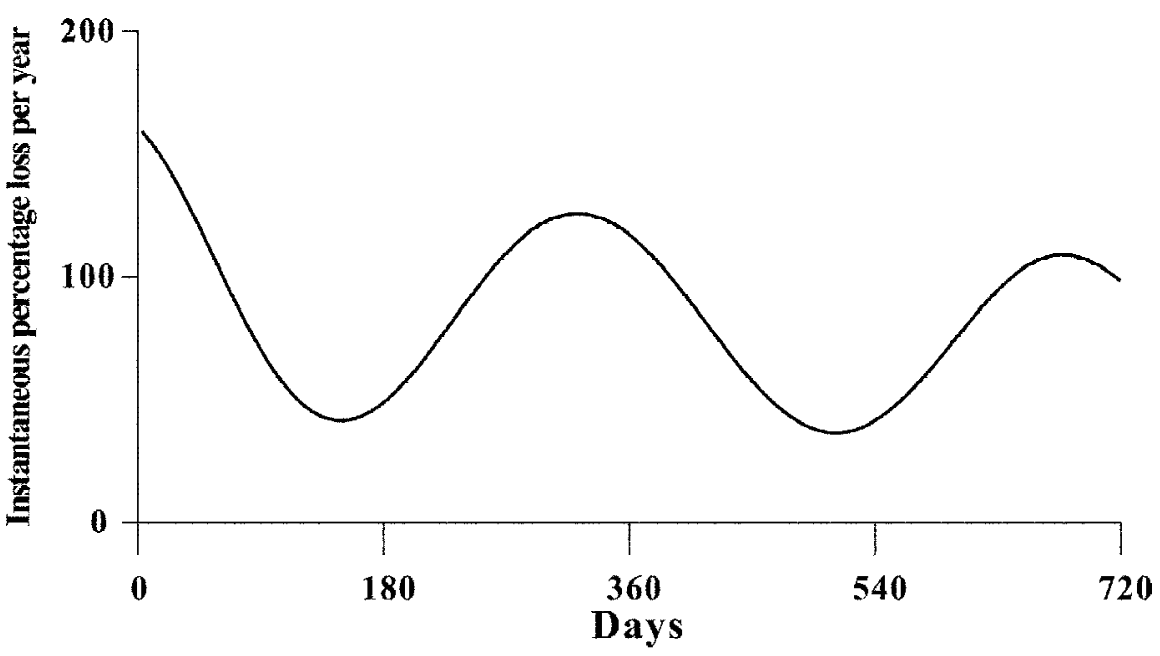

Fig. 14. Percentage loss of total tracer concentrations in the Yellow Sea and Bohai as a function of time. The time spans the first two years of tracer release. 


\section{DISCUSSIONS AND CONCLUSIONS}

The sensitivity of circulation in surrounding seas to the Yangtze River discharge is examined using a regional ocean circulation model (Lee and Chao 2003). The model is an improvement over previous modeling work on the similar subject by Delcroix and Murtugudde (2002), which used coarse $\left(1 / 4^{\circ} \sim 1 / 2^{\circ}\right)$ resolution and truncated ocean margins shallower than the mixed layer depth. Off the China coast, nearshore areas shallower than about $40 \mathrm{~m}$, Bohai and the northern portion of the Yellow Sea were treated as landmasses. The present model retain these coastal features and uses a final $\left(1 / 6^{\circ}\right)$ resolution, In consequence, more details come to light. For example, the summer Yangtze River plume does not extend as eastward as in Delcroix and Murtugudde (2002). Rather, the dispersal is more northeastward and well into the southern reaches of the Yellow Sea. The winter coastal jet to the south of Yangtze River mouth is much better developed, becoming narrower and swifter. The model is also an improvement over Lee and Chao (2003). Through a sizable reduction of the bottom drag coefficient, the improved model is able to capture major frontal features in the transition region between the Yellow Sea and East China Sea.

With northeastward dispersal in summer and southward dispersal in winter in normal years, a good portion of the summer Yangtze plume stays in the southern Yellow Sea and Northern East China Sea until the end of fall, unable to disperse away effectively. The northerly monsoon in winter produces the CCC which carries the Yangtze River discharge southward. Further, the southern Yellow Sea and northern East China Sea waters, which contain remnants of Yangtze River plume from the preceding summer, also begin to move southward with the CCC. In other words, the area bordering the Yellow Sea and the East China Sea serves as a reservoir which retains summer Yangtze discharge and releases it into the CCC in winter. The winter CCC therefore contains both the newly discharged Yangtze River water and vintage Yangtze River water from the preceding summer.

Because of the delayed release of the summer Yangtze River plume water to the southern East China Sea, a reduced Yangtze River outflow produces highly asymmetric seasonal effects. We have reduced the discharge by the same percentage each month to illustrate these effects. In summer, a reduced outflow induces an expansive and strong positive salinity anomaly to the northeast of the river mouth. The response is rather swift and proportional to the amount of outflow reduction. In winter, the southward advection of fresher water by the CCC is rather insensitive to a reduction of Yangtze River outflow. This does not come as a surprise because the CCC is mostly a wind-driven coastal current which does not owe its existence to the Yangtze River outflow. Further, remnants of the Yangtze River water retained in the southern Yellow Sea and northern East China Sea from the preceding summer help replenish the CCC if the winter Yangtze runoff is reduced. These two factors reduce the impact of decreased Yangtze River outflow to the CCC in winter. In the highly unlikely event that Yangtze runoff is completely terminated for multiple years, the Yellow Sea and even Bohai waters will become the major source of the CCC in the southern East China Sea. The changeover may have profound impacts to the biogeochemistry of the southern East China Sea. In terms of flow fields, however, changes in the southern East China Sea are relatively minor.

Much more effort is needed along this line of investigation. For example, the sensitivity 
of water mass characteristics in the Yellow Sea and Bohai to the reduced Yangtze outflow needs to be explored. Concerning the northward excursion of the Taiwan Warm Current, the possible alteration by the Yangtze outflow reduction is also an important issue yet to be addressed. A coupled model of physics and biology is in need of development to address possible future changes in the biogeochemistry of surrounding seas. Our efforts are ongoing.

Acknowledgments Author HJL was supported by a contract from the National Science Council, R.O.C., under grant NSC 92-2611-M-291-001. KKL was supported by the grant NSC 922611-M-008-006.

\section{REFERENCES}

Beardsley, R. C., R. Limeburner, H. Yu, and G. A. Cannon, 1985: Discharge of the Changjiang (Yangtze River) into the East China Sea. Cont. Shelf Res., 4, 57-76.

Chen, C. T. A., 2000: The Three Gorges Dam: Reducing the upwelling and thus productivity in the East China Sea. Geophys. Res. Letters, 27, 3, 381-383.

Delcroix, T., and R. Murtugudde, 2002: Sea surface salinity changes in the East China Sea during 1997-2001: Influence of the Yangtze River, J. Geophys. Res., 107, C12, 8008, doi:1029/2001JC000893.

Edmond, J. M., A. Spivack, B. C. Grant, M.-H. Hu, Z. Chen, S. Chen, and X. Zeng, 1985: Chemical dynamics of the Changjiang estuary. Cont. Shelf Res., 4, 17-36.

Gong G. C., Y. L. L. Chen, and K. K. Liu, 1996: Chemical hydrography and chlorophyll distribution in the East China Sea in summer: implications in nutrient dynamics. Cont. Shelf Res., 16, 1561-1590.

Gong, G. C., Y. H. Wen, B. W. Wang, and G. J. Liu, 2003: Seasonal variation of chlorophyll a concentration, primary production and environmental conditions in the subtropical East China Sea, Deep-Sea Res. II, 50, 1219-1236.

Hellerman, S., and M. Rosenstein, 1983: Normal monthly wind stress over the world ocean with error estimates. J. Phys. Oceanogr., 13, 1093-1104.

Huang, H. J., F. Li, and X. R. Zhang, 2001: Water and sediment discharges from the Changjiang and Huanghe Rivers: a comparative study (in Chinese). In: Hu, D. X., Zhang, S., and Han, W. Y. (Eds.), Land-ocean interaction in the estuaries of the Changjiang and Pearl Rivers and the adjoining regions. China Ocean Press, Beijing, 36-49.

Lee, H. J., and S. Y. Chao, 2003: A climatological description of circulation in and around the East China Sea, Deep-Sea Res. II, 50, 1065-1084.

Levitus, S., and T. Boyer, 1994: World ocean atlas 1994 volume 4. NOAA Atlas NESDIS 4, U. S. Department of Commerce, Washington, D. C., http://ingrid.ldgo.columbia.edu / SOURCES/.LEVITUS94/.

Lie, H. J., C. H. Cho, J. H. Lee, P. Niiler, and J. H. Hu, 1998: Separation of the Kuroshio water and its penetration onto the continental shelf west of Kyushu.J. Geophys. Res. 103, 2963-2976. 
Lie, H. J., C. H. Cho, J. H. Lee, S. Lee, Y. Tang, and E. Zou, 2001: Does the Yellow Sea Warm Current really exist as a persistent mean flow? J. Geophys. Res. 106, 2219922210.

Liu K. K., and K. C. Chen, 2002: Residence time of the East China Sea shelf waters. EOS Trans. Am. Geophys. Union 83 (4), Ocean Sciences Meeting Suppl., OS6.

Mask A. C., J. J. O'Brien, and R. Preller, 1998: Wind-driven effects on the Yellow Sea Warm Current, J. Geophys. Res., 103, 30713-30729.

Milliam, J. D., 1997: Blessed dams or dammed dams. Nature, 386, 325-326.

Naimie, C. E., C. A. Blain, and D. R. Lynch, 2001: Seasonal mean circulation in the Yellow Sea - a model-generated climatology, Cont. Shelf Res., 21, 667- 695.

Pacanowski, R. C., and S. G. H. Philander, 1981: Parameterization of vertical mixing in numerical models of tropical ocean. J. Phys. Oceanogr., 11, 1443-1451.

Sarmiento, J. L., and K. Bryan, 1982: An ocean transport model for the North Atlantic.J. Geophys. Res., 87, 394-408.

Semtner, A. J., 1974: An oceanic general circulation model with bottom topography. Technical Report 9, Department of Meteorology, University of California, Los Angeles, 99pp.

$\mathrm{Su}$, J., 1998: Circulation dynamics of the China Seas north of $18^{\circ} \mathrm{N}$. In: Robinson, A. R., and K. H. Brink, (Eds.), The Sea, Vol. 11. Wiley, New York, 483-505.

Tsunogai, S., S. Watanabe, and T. Sato, 1999: Is there a "continental shelf pump" for the absorption of atmospheric $\mathrm{CO}_{2}$ ? Tellus, 51, 701-712.

Zhang, J. 1996: Nutrient elements in large Chinese estuaries. Cont. Shelf Res., 16, 1023-1045.

Zhang, J., R. Letolle, J. M. Martin, C. Jusserand, and J. M. Mouchel, 1990: Stable oxygen isotope distribution in the Huanghe (Yellow River) and the Changjiang (Yangtze River) estuarine systems. Cont. Shelf Res., 10, 369-384. 